\title{
Health provider networks, quality and costs*
}

\author{
Jan Boone and Christoph Schottmüller ${ }^{\dagger}$
}

January 12, 2015

\begin{abstract}
We provide a modeling framework to think about selective contracting in the health care sector. Two health care providers differ in quality and costs. When buying health insurance, consumers observe neither provider quality nor costs. We derive an equilibrium where health insurers signal provider quality through their choice of provider network. Selective contracting focuses on low cost providers. Contracting both providers signals high quality. Market power tends to lower quality and lead to inefficiency. In a dynamic extension of the model, providers under-invest in quality while there can be both over and under-investment in cost reductions if there is a monopoly insurer while an efficient investment equilibrium exists with insurer competition.
\end{abstract}

Keywords: selective contracting, exclusive contracts, common contracts, managed care, health care quality, signaling

JEL classification: D86, I11, L13

\footnotetext{
${ }^{*}$ We thank seminar audiences at the University of Copenhagen for comments. Financial support from the Dutch National Science Foundation (VICI 453.07.003) is gratefully acknowledged.

${ }^{\dagger}$ Boone: Department of Economics, University of Tilburg, P.O. Box 90153, 5000 LE, Tilburg, The Netherlands; Tilec, CentER and CEPR; email: j.boone@uvt.nl. Schottmüller: Department of Economics, University of Copenhagen, Øster Farimagsgade 5, building 26, DK-1353 Copenhagen K, Denmark; Tilec; email: christoph.schottmuller@econ.ku.dk.
} 


\section{Introduction}

Selective contracting in health care markets is the practice where an insurer limits the choice of providers that can be visited by the insured when they need treatment. Among the advantages claimed for selective contracting is the potential to "weed out providers who would be poor choices for plan members, for reasons of either quality or cost" (McGuire, 2011b, pp. 366).

There is quite some evidence that selective contracting helps to reduce costs. When managed care was introduced in California in the 1980s, hospital prices tended to fall (Dranove et al., 1993). Chernew and Newhouse (2011, pp. 30) conclude from a literature overview that the "central findings from these studies were that hospital cost and revenue growth slowed markedly following the introduction of selective contracting". The economic rationale for this is intuitive. Insured patients do not worry (much) about the cost of a treatment and hence do not shop around for a low cost provider. If an insurer allows its customers to visit any provider, at least some of them visit inefficient ones. One way to avoid this, is for the insurer to selectively contract the most efficient providers and exclude inefficient providers from the network (Dranove, 2000, pp. 72-74).

Why selective contracting should help to raise quality is not as clear compared to its effect on costs. Indeed, unlike provider cost, the patient is directly interested in provider quality. If one provider offers higher quality than another, an informed patient tends to choose the former. Although quality information may not be easily available, patients can learn from others' experiences or decide which specialist to visit based on the advise of a primary physician.

However, there is a difference here between deciding which provider to visit once you know which treatment you need and deciding which providers to exclude at the moment that you buy insurance. If an insurer excludes some providers, can this be a credible signal to consumers that the excluded providers have lower quality than the ones in the network? Or does a consumer conclude that the insurer excludes high quality providers which tend to be more expensive; just to keep costs down?

This debate has also reached the popular press. Pear (2014) writes "insurers say, when they are selective, they can exclude lower-quality doctors and hospitals". Terhune (2013) cites Donald Crane, chief executive of the California Association of Physician Groups, asking: "We are nervous about these narrow networks. It was all about price. But at 
what cost in terms of quality"?

Evidence of the effects of selective contracting on quality is mixed (Cutler, 2004, chapter 8) 1 A number of authors have argued that selective contracting tends to reduce quality. To illustrate, although selective contracting (and managed care more generally) was seen as a success in the US in the 1980s and early 1990s, it "deteriorated into a zerosum competition over cost shifting, with patients the ultimate losers as quality suffered" (Porter and Teisberg, 2006, pp. 77). Zwanziger et al. (2000) argue that it is unclear whether the cost reductions mentioned above were due to increased efficiency or lower quality. Finally, some have argued that when doctor's decisions are affected by financial incentives - like the threat to be excluded by the insurer - this tends to reduce quality (Stone, 1997).

Our paper offers a framework to think about these issues. We introduce a model with two providers who can have different treatment cost and quality levels. These providers bargain with an insurer and the insurer can decide to contract both providers or only one. In the latter case, there is an exclusive contract between the insurer and (contracted) provider; we refer to this as selective contracting. In the former case, there are common contracts and the provider network consists of both providers. The bargaining between insurer and providers is modelled as in Bernheim and Whinston (1998) [henceforth, BW].

The consumer observes neither providers' quality nor cost when buying insurance. If a patient needs treatment and his insurance contract covers both providers, he consults with his GP to decide which provider to visit. We assume that the GP points him to the higher quality provider, if quality levels differ. In this setting, what is the effect of selective contracting on health care quality and costs? For example, can an insurer signal high quality by selectively contracting one provider?

We find that selective contracting signals a focus on costs, while common contracts signal quality. In particular, we distinguish two types of provider cost-quality configurations. In the insurer-critical configuration, letting the insurer choose the provider (through selective contracting) leads to inefficiency: quality is too low (from a social/efficiency point of view). In the patient-critical configuration, letting the patient choose the provider leads to inefficiently high costs. Hence, an efficient outcome requires an equilibrium where both

\footnotetext{
${ }^{1}$ Himmelstein et al. (1999) warn that some of the early comparisons between HMOs using selective contracting and indemnity insurance used not-for-profits HMOs. They provide evidence that for-profits HMOs tend to offer lower quality than not-for-profits HMOs and therefore lower quality than indemnity insurance which does not exclude providers.
} 
providers are contracted in insurer-critical configurations while there is selective contracting in patient-critical configurations. We show that with insurer competition such an efficient outcome is feasible. Market power, either on the insurer or the provider side, makes an efficient outcome less likely. We extend this (static) result to dynamic efficiency in the following sense. Suppose providers can invest to raise quality and reduce costs. With insurer competition there exists an equilibrium where investments are chosen efficiently. With a monopoly insurer there is under-investment in quality by the providers.

There are two strands of literature related to our approach. First, there is a literature on incentives under managed care which considers aspects of managed care that we do not focus on. One aspect of managed care is a move away from simple fee-for-service contracts and allow for more elaborate supply side management. To illustrate, capitation contracts can be used to reduce over-supply of medical services. A recent overview of physician agency can be found in McGuire (2011a). In Ma and McGuire (2002) managed care plans ration treatments by threatening to (partially) exclude physicians with treatment costs above the target. In our model there is no decision margin with respect to treatment: patients get treated if and only if they need it. Selective contracting (applied to drugs) is discussed in McGuire (2011b). There it helps to reduce drug prices, but there is no quality aspect. Moreover, the framework is not rich enough to allow for a common outcome where more than one (substitute) drug is contracted. As BW do allow for common outcomes, we follow their set up.

If we interpret selective contracting as a way to intensify (payer driven) provider competition, our results are in line with Gavnor (2006). He finds that more intense provider competition tends to raise quality if treatment prices are regulated. Indeed, in our model with regulated provider prices, an insurer contracts exclusively with the high quality provider. As prices are regulated, the insured do not need to worry that the cheapest (low quality) provider is contracted.

Finally, we assume all insured are the same. Hence, there is no effect of network size on the type of customers buying insurance. Bardey and Rochet (2010) analyzes a managed care organization as a two sided platform: attracting both providers and customers buying insurance. Offering a broader network can attract insured with higher health risk (adverse selection). If this effect is strong enough, offering a narrow network through selective contracting is optimal.

Rey and Tirole (2007) give an overview of different approaches towards exclusive con- 
tracting. As mentioned, we follow the BW approach to model the bargaining between providers and insurer, where providers offer simultaneously both exclusive and common contracts and the insurer decides which to accept. This allows us to immediately capture a result on contracted prices by Cutler et al. (2000): HMOs lead to lower health care expenditure through negotiating lower prices with providers (not through reducing the number of treatments). We know from BW that a common contract (if it can be sustained as equilibrium) leads to higher transfers and payoffs for the providers. The insurer instead prefers the exclusive outcome where competition between providers brings prices down. We extend BW in two directions. First, common and exclusive outcomes affect industry profits by affecting consumers' beliefs about (contracted) provider quality. Hence, the equilibrium choice of contracts is used as a signalling device. Whereas standard signalling models have one agent who takes a "signalling action", here it is the interplay of the providers and insurer that sends a signal. Second, we allow for two insurers bargaining at the same time with the two providers; BW - in our terminology - only consider simultaneous bargaining between two providers and one insurer. We show that insurer competition leads to better signalling and hence a more efficient outcome.

This paper is organized as follows. The next section introduces the model. Then we analyze the insurer monopoly case and show that the outcome is not necessarily efficient. Section 4 shows that there is always an efficient equilibrium with insurer competition. But provider market power can destroy efficiency even with insurer competition. Then we endogenize costs and quality by allowing providers to invest to raise quality and reduce costs. We conclude by discussing the policy implications of our approach.

\section{Model}

The basic model has four players: one consumer, one insurer and two providers. The consumer buys insurance and consumes medical services. We assume that insurance always covers all medical expenses. The consumer receives a utility equal to the quality of treatment $q$ (when ill) minus the insurance premium $\sigma$ that he pays. To simplify notation we assume that the consumer needs one treatment with probability one (otherwise we would have to work with expectations throughout the paper which would complicate the notation without changing the analysis). If the consumer remains uninsured we assume that he has no access to health care and his payoff is 0. Consequently, a consumer buys 
an insurance policy if he believes that the quality in the offered contract is higher than the premium.2

The insurer contracts with the consumer and two health care providers. A contract with the consumer specifies a premium and a set of providers from which the consumer can choose when falling ill. A contract with a provider specifies a payment from the insurer to the provider, this payment is a two-part tariff. The fixed part is a capitation fee: the insurer pays the provider $t$ for each of its insured, independent from treatment 3 When a patient is treated, the provider receives a fee-for-service $p$ from the insurer. Note that when the insurer contracts both providers ("common outcome" in BW terminology) the capitation fee and fee-for-service are not equivalent because capitation is paid to both providers while fee-for-service is only paid to the provider treating the patient. The insurer maximizes expected profits. Initially, we look at a situation where there is only one insurer ("monopoly"). Then we consider a competitive insurance market ("duopoly" of insurers $A$ and $B)$.

Provider $i=1,2$ has a quality $q^{i} \in Q=\left\{q_{1}, q_{2}, \ldots, q_{n}\right\}$ where $q_{1}<q_{2}<\cdots<q_{n}$ and a cost of service $c^{i} \in C=\left\{c_{1}, c_{2}, \ldots, c_{m}\right\}$ where $c_{1}<c_{2}<\cdots<c_{m}$. In some examples, we restrict ourselves to $n=m=2$ and then write $Q=\left\{q^{l}, q^{h}\right\}$ with $q^{l}<q^{h}$ and $C=\left\{c^{l}, c^{h}\right\}$ with $c^{l}<c^{h}$. Providers offer contracts to insurers. They can offer an exclusive contract which specifies the terms in case the insurer contracts only with this provider. They can also offer a common contract which specifies terms in case the insurer contracts with both providers. As in BW, we allow providers to offer both an exclusive and a common contract. If the insurer accepts an exclusive contract, there is selective contracting with this provider.

The information structure is that providers and insurers are perfectly informed about $q^{i}$ and $c^{i}$ but the consumer does not know these parameters 4 The consumer has a non-

\footnotetext{
${ }^{2}$ We abstract from risk aversion and other motives to buy insurance. The reason is that our focus is the contracting between providers and insurers and we consequently want to keep the consumer side of the model as simple as possible. The important part of the consumer is that quality matters for his purchasing decision and a monopolist insurer cannot charge an infinite premium without losing demand. For an analysis of the effect of selective contracting on the uninsured market, see Bijlsma et al. (2009).

${ }^{3}$ Just to be clear: if the consumer does not sign up for the insurer's insurance policy, the insurer does not pay the capitation fee to the provider.

${ }^{4}$ That insurers can observe costs is not important in the following analysis because we model the interaction with providers as a bidding game - where providers make the offers - and $c^{i}$ is irrelevant for the insurer's or consumer's payoff.
} 
degenerated prior $F$ on $\left(q^{1}, c^{1}, q^{2}, c^{2}\right)$ with $q^{1}, q^{2} \in Q$ and $c^{1}, c^{2} \in C$. Put differently, every $\left(q^{1}, c^{1}, q^{2}, c^{2}\right)$ with $q^{i} \in Q$ and $c^{i} \in C$ has strictly positive probability, denoted $f\left(q^{1}, c^{1}, q^{2}, c^{2}\right)>0$. We assume that $F$ is symmetric: $f(\tilde{q}, \tilde{c}, \hat{q}, \hat{c})=f(\hat{q}, \hat{c}, \tilde{q}, \tilde{c})$. Note that this allows for correlation between $q^{i}$ and $c^{i}$ but also for correlation between $q^{1}$ and $q^{2}$ etc. To illustrate, a positive correlation between $c^{i}$ and $q^{i}$ implies that quality costs money. To provide high quality, a provider has to spend more resources. A negative correlation between $c^{i}, q^{i}$, on the other hand, can be interpreted as high quality treatments leading to fewer complications (lower re-admissions) and hence lower costs. Alternatively, a well run hospital manages to provide high quality at low costs. Badly run hospitals provide low quality at high costs. Positive correlation between $q^{1}$ and $q^{2}$ (or between $c^{1}, c^{2}$ ) is caused by some common factor: new technology being adopted that increases quality in both hospitals etc. We use "configuration" to refer to a realization $\left(q^{1}, c^{1}, q^{2}, c^{2}\right)$ of $F$.

Contract offers by providers are only observed by the provider making the offer and the insurer receiving the offer but not by the other provider (or other insurer in case of duopoly). The consumer does not observe contracts between providers and insurers. Indeed, in reality these contracts are private due to confidentiality clauses which are guarded aggressively by both parties involved (Muir et al., 2013).

The timing is the following. First, providers simultaneously and independently offer contracts to the insurer(s). Second, insurers simultaneously and independently accept or reject these offers. These first two steps follow BW. Third, insurer(s) simultaneously and independently offer health insurance contracts (specifying a premium and provider network) to consumers. While offering these insurance policies, insurers do not know the details of each others' contracts. Rey and Vergé (2004) call this interim unobservability. The consumer updates his beliefs about quality given the offered policies and chooses one of the offered policies (or remains uninsured).

We make the following assumption on the consumer's information. When the consumer buys insurance, he does not know the quality of the providers. When the consumer falls ill (after he has bought an insurance contract) and becomes a patient, he is able - when given the choice - to choose the provider with higher quality. One way to think about this is the following. Once an agent falls ill, he consults with his GP to choose which hospital to go to. If there is choice, we assume that the GP acts in the patient's best interest and she advices him to go to the provider with highest quality. As the patient does not pay 
for treatment, the GP does not take costs into account 5

Alternatively, one can think of this as "word of mouth" where a patient learns from friends and neighbours what the better hospital is for a given treatment. When buying insurance, the consumer does not know yet which treatment he needs and a hospital might be of "high" or "low" quality depending which treatment is needed, e.g. a hospital that is very good at open heart surgery can be bad at cancer care. Hence, word of mouth works better ex post (when the patient knows which treatment is needed) than ex ante (when he buys insurance).

Our solution concept is perfect Bayesian Nash equilibrium to which we refer as "equilibrium". Our main focus is efficiency. We call an equilibrium efficient if for any $\left(q^{1}, c^{1}, q^{2}, c^{2}\right)$ the consumer is treated by the provider $i \in \arg \max _{j} q^{j}-c^{j}$. That is, the provider that treats the patient provides a social surplus at least as high as the other provider. We assume that medical care is always beneficial and therefore remaining uninsured is never efficient. More precisely, we assume $q_{1}>c_{m}$.

Assumption 1 There exist $q_{w}, q_{x} \in Q$ and $c_{y}, c_{z} \in C$ such that $q_{w}-c_{y}>q_{x}-c_{z}$ and $c_{y}>c_{z}$.

In words, there is at least one configuration in which the cost criterion and the welfare criterion are not aligned. We call this an insurer-critical configuration. The insurer minimizing costs - sends the patient to one provider, but social welfare is higher if the patient is treated by the other provider. In a patient-critical configuration the quality and welfare criterion are not aligned. An insured patient chooses the provider with highest quality (as he does not care about costs) while the other provider offers higher social surplus $q-c$. This is the traditional argument in favour of selective contracting (Dranove, 2000, pp. 72-74). Formally, there can be $q_{w}, q_{x} \in Q$ and $c_{y}, c_{z} \in C$ such that $q_{w}-c_{y}>q_{x}-c_{z}$ and $q_{w}<q_{x}$. In this case, when both providers are contracted, the patient chooses the provider with $q_{x}, c_{z}$ while the other provider yields higher social surplus 6

\footnotetext{
${ }^{5}$ In principle, the consumer when buying insurance could consult his GP to decide which providers should be contracted. This is quite a task as the best provider can differ for different treatments. Consequently, very few people do this. Moreover, doctors do not want to give advice on this (Liebman and Zeckhauser, 2008, pp. 7).

${ }^{6}$ If $q_{w}=q_{x}$ and $c_{y}<c_{z}$ an insured patient is indifferent between providers and chooses the (socially) inefficient one with probability $\frac{1}{2}$. To simplify the exposition, we will refer to a situation with $q^{1}=q^{2}$ and $c^{1} \neq c^{2}$ as "patient-critical configuration" in the $n=m=2$ case.
} 
In the patient critical configuration, a co-payment can ensure that the patient visits the efficient provider. Co-payments introduce a trade off between efficiency and insurance that we do not consider 7 Here we focus on network choice as a signal of quality.

\section{Insurer monopoly}

In this section, we focus on a monopoly insurer. As an introduction to the model, we simplify the exposition by assuming $m=n=2$. Assumption 1 1 then implies $q^{h}-c^{h}>q^{l}-c^{l}$.

The first question is: does an equilibrium exist? Using BW, the answer is: yes. There always exists an equilibrium in which both providers offer the insurer an exclusive contract in every possible configuration. Clearly, this is a Nash equilibrium: given that one provider only offers an exclusive contract, the other provider's optimal response is to offer an exclusive contract as well. As the consumer cannot observe the contracted provider's quality, he values an insurance contract with an exclusive provider at $q^{E}$, independent of the identity of the contracted provider. This implies that the insurer contracts the provider that leaves it with the highest rent. One way to implement this equilibrium is $t_{1}=t_{2}=0, p_{1}=p_{2}=\max \left\{c^{1}, c^{2}\right\}$. The insurer contracts the provider with lowest cost 8 This outcome corresponds to Bertrand competition between providers. If both providers have the same cost, the insurer is indifferent and contracts the provider with the highest quality. If both costs and quality levels are the same, the insurer randomizes. Consumer's expectation of provider quality, conditional on the insurer's network (always) consisting of one provider is given by

$$
q^{E}=q^{h}-\left(q^{h}-q^{l}\right)\left(2 f\left(q^{l}, c^{l}, q^{h}, c^{h}\right)+\sum_{c, c^{\prime} \in C} f\left(q^{l}, c, q^{l}, c^{\prime}\right)\right) .
$$

That is, quality is high, unless either of the following two cases applies. First, the insurer critical configuration where the low cost, low quality provider is contracted (instead of the efficient provider). Second, the case where both providers have low quality. The monopoly insurer sets its premium at $\sigma^{E}=q^{E}$. Industry profits equal $\Pi^{E}=q^{E}-\min \left\{c^{1}, c^{2}\right\}$ as

\footnotetext{
${ }^{7}$ In particular, a patient may have a preference for a certain hospital (irrespective of quality), say due to travel costs. Then providers' cost difference needs to be weighed against this travel cost. To make the patient choose efficiently, this would require a co-payment of the order $c_{z}-c_{y}$ which may be substantial and reduce the value of insurance.

${ }^{8}$ If there is a smallest currency unit $\varepsilon>0, p_{1}=c^{2}-\varepsilon$ and $p_{2}=c^{2}$ for $c^{1}<c^{2}$ will be an equilibrium in which the insurer strictly prefers the provider with the lower costs.
} 
the low cost provider treats the patient. The insurer gets $\pi_{I}^{E}=q^{E}-\max \left\{c^{1}, c^{2}\right\}$, the contracted provider $i$ gets $\pi_{i}^{E}=\max \left\{c^{1}, c^{2}\right\}-\min \left\{c^{1}, c^{2}\right\}$ and the excluded provider receives zero profits.

As noted in BW, this is the exclusion equilibrium in undominated strategies. If $c^{1}<c^{2}$, there are also exclusion equilibria with $t_{1}=t_{2}=0$ and $p_{1}=p_{2}=p \in\left[c^{1}, c^{2}\right\rangle$ and the insurer contracts provider 1 . Profits in such an equilibrium equal $\pi_{I}=q^{E}-p, \pi_{1}=$ $p-c^{1}, \pi_{2}=0$. Provider 2 , by bidding $p<c^{2}$, uses a weakly dominated strategy.

There always exists an equilibrium with exclusive contracts, but it is not efficient. In the insurer-critical configuration $\left(q^{h}, c^{h}, q^{l}, c^{l}\right)$, the insurer contracts the inefficient low cost provider. The reason is that the consumer cannot distinguish an exclusive contract with a low quality provider from a contract with a high quality provider. Hence, any exclusive contract is valued at $q^{E}$. The insurer sets premium $\sigma^{E}=q^{E}$ and minimizes costs by choosing the low cost, low quality provider. In this sense, exclusive contracts or selective contracting is cost focused and can lead to inefficiently low quality.

This inefficiency is likely to occur if $q^{i}, c^{i}$ are positively correlated; that is, in case quality requires resources. If, instead, this correlation is negative (well run hospitals provide high quality at low costs) the expected welfare loss due to selective contracting (in every configuration) is small.

The way to overcome this inefficiency is to give the insured choice: contract both providers and let the patient choose his provider ex post when he is better informed (e.g. advised by his primary physician). In other words, high quality is signalled by the insurer contracting both providers. This the opposite of the idea mentioned in the introduction that selective contracting is used by insurers to guide insured to high quality providers.

We know from BW (page 70/1) that an equilibrium with common contracts exists if and only if the common industry profits $\left(\Pi^{C}\right)$ exceed the exclusive industry profits $\left(\Pi^{E}\right)$ :

$$
\Pi^{C} \geq \Pi^{E} .
$$

To see this, suppose - by contradiction - that $\Pi^{E}>\Pi^{C}$ and a common equilibrium exists. Assume that the exclusive contract between provider 1 and the insurer yields industry profits $\Pi^{E}$. Since $\pi_{1,2, I} \geq 0$ for each player $1,2, I$, we find that

$$
\pi_{1}^{E}+\pi_{I}^{E}=\Pi^{E}>\Pi^{C}=\pi_{1}^{C}+\pi_{2}^{C}+\pi_{I}^{C} \geq \pi_{1}^{C}+\pi_{I}^{C} .
$$

Hence, by using two part-tariffs, provider 1 can make $I$ a deviating (exclusive) offer that increases their joint payoffs. The fixed part of the tariff can be used to ensure that both 
$\pi_{1}^{E} \geq \pi_{1}^{C}$ and $\pi_{I}^{E} \geq \pi_{I}^{C}$. I accepts such an offer. Hence, there is no common equilibrium if $\Pi^{C}<\Pi^{E}$.

To get efficiency, we need to sustain common equilibria. In particular, both providers need to be contracted in insurer critical configurations. Therefore, we make $\Pi^{C}$ as high as possible while keeping $\Pi^{E}$ as low as possible such that (2) is satisfied. This translates into making $q^{C}$ as high as possible while keeping $q^{E}$ as low as possible. Consider table 1 to see how $q^{E}$ and $q^{C}$ are determined.

Table 1: Efficient contracts in each configuration: Common and Exclusive

\begin{tabular}{|c|c|c|c|c|c|}
\hline & \multicolumn{4}{|c|}{ Provider 2} \\
\hline & & $c_{l}, q_{l}$ & $c_{l}, q_{h}$ & $c_{h}, q_{l}$ & $c_{h}, q_{h}$ \\
\hline \multirow{4}{*}{ 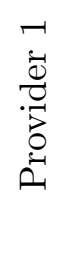 } & $c_{l}, q_{l}$ & $\mathrm{E}$ & $\mathrm{C}$ & $\mathbf{E}$ & $\mathrm{C}$ \\
\hline & $c_{l}, q_{h}$ & $\mathrm{C}$ & $\mathrm{C}$ & $\mathrm{C}$ & $\mathbf{E}$ \\
\hline & $c_{h}, q_{l}$ & $\mathbf{E}$ & $\mathrm{C}$ & $\mathrm{E}$ & $\mathrm{C}$ \\
\hline & $c_{h}, q_{h}$ & C & $\mathbf{E}$ & $\mathrm{C}$ & $\mathrm{C}$ \\
\hline
\end{tabular}

To get efficiency, we need common contracts in insurer-critical configurations; these are the bold $\mathbf{C}$ in table 1, In patient-critical configurations, we need an exclusive outcome; the bold $\mathbf{E}$ in the table. In these cases, the patient is indifferent between providers and randomizes. This implies that with common contracts there is $50 \%$ probability that he visits the high cost provider which is inefficient. To avoid this, an exclusive contract is needed. In the 10 remaining configurations, we are free to choose whether the outcome is $\mathrm{C}$ or $\mathrm{E}$ : as long as it can be sustained as an equilibrium. As we argued above, an exclusive equilibrium always exists. We show in the proof of the following proposition that a common equilibrium exists in every other configuration denoted $\mathrm{C}$ in table 1 if a common equilibrium exists in the insurer-critical configuration 9 Hence, for the non-bold entries in the table, we are free to choose either $\mathrm{C}$ or $\mathrm{E}$. There can be multiple equilibria here. We characterize an efficient equilibrium.

To maximize $q^{C}-q^{E}$, we choose the equilibrium with $C$ for each of the ten remaining configurations in table 1 where the resulting quality for the patient is $q^{h}$. If the resulting quality is $q^{l}$, we choose $E$. As a consequence, we find for table 1 that after observing $C, E$

\footnotetext{
${ }^{9}$ Note that also in a $\mathrm{C}$ outcome providers make exclusive offers. Indeed, the exclusive offer of provider $j$ determines how much surplus provider $i$ gets in a $\mathrm{C}$ outcome.
} 
resp. the consumer updates his belief on the treatment quality he will receive to

$$
\begin{aligned}
& q^{C}=q^{h} \\
& q^{E}=\frac{2 q^{h} f\left(q^{h}, c^{h}, q^{h}, c^{l}\right)+q^{l} \sum_{x, y \in\left\{c^{h}, c^{l}\right\}} f\left(q^{l}, x, q^{l}, y\right)}{2 f\left(q^{h}, c^{h}, q^{h}, c^{l}\right)+\sum_{x, y \in\left\{c^{h}, c^{l}\right\}} f\left(q^{l}, x, q^{l}, y\right)} .
\end{aligned}
$$

If the outcome in the table is an equilibrium, a consumer buying insurance with two providers in the network knows for sure that he gets quality $q^{h}$ when treated. If the consumer buys insurance where only one provider is contracted, quality can be either $q^{h}$ or $q^{l}$. Equation (5) gives the expected quality conditional on buying insurance which covers only one provider.

In the efficient outcome in the table, we are likely to see selective contracting if $q^{1}, q^{2}$ are positively correlated. Indeed, E only happens if $q^{1}=q^{2}$. In case $q^{1} \neq q^{2}$ we have $\mathrm{C}$ in the efficient outcome. The idea that selective contracting is important if providers' qualities differ is not correct in the efficient outcome; i.e. selective contracting is useful to select a low cost provider but not useful to select a high quality provider.

It turns out that the efficient outcome in table 1 is an equilibrium outcome, if $c^{h}-c^{l}$ is not too big 10

Proposition 1 With a monopoly insurer, an efficient equilibrium exists if and only if

$$
q^{h}-q^{l} \geq\left(1+\frac{2 f\left(q^{h}, c^{h}, q^{h}, c^{l}\right)}{\sum_{x, y \in\left\{c^{h}, c^{l}\right\}} f\left(q^{l}, x, q^{l}, y\right)}\right)\left(c^{h}-c^{l}\right) .
$$

Note that we assume $q^{h}-q^{l}>c^{h}-c^{l}$, but this still leaves values for $q^{h, l}, c^{h, l}$ such that (6) is not satisfied.

The higher $f\left(q^{h}, c^{h}, q^{h}, c^{l}\right)$ compared to the probability that both providers have low quality, the higher $q^{E}$ and the less likely that an efficient equilibrium exists. That is, if both providers are likely to be high quality, while their cost levels are negatively correlated, it is unlikely that a monopoly insurer can sustain the efficient outcome.

To see the intuition for the proposition, we ask whether equation (21) is satisfied in the insurer-critical configuration. The common insurance contract is sold at premium $\sigma^{C}=q^{C}=q^{h}$. If $q^{h}$ is high, this common contract creates high industry profits. The benefit of an exclusive contract in this configuration is the cost saving $c^{h}-c^{l}$; the cost

\footnotetext{
${ }^{10}$ Although we work with $m=n=2$ here, it is straightforward that the proposition extends to the case $n, m \geq 2$. Efficient equilibria similar to the one constructed in table 1 will exist for some parameter values but not for all.
} 
to the industry of an exclusive contract is the lower premium $\sigma^{E}=q^{E}<q^{C}$. If $q^{h}-q^{l}$ is sufficiently large compared to $c^{h}-c^{l}$, the cost of $\mathrm{E}$ is big compared to the benefit: $\mathrm{C}$ can be sustained in the insurer-critical configuration. If (6) is not satisfied, E dominates $\mathrm{C}$ in terms of industry profits and it is not possible to sustain an efficient outcome with a monopoly insurer.

The existence of an efficient equilibrium depends on whether $q^{C}-q^{E}$ exceeds the cost saving $c^{h}-c^{l}$ in the insurer critical configuration. The logic of proposition 1 implies the following result.

Corollary 1 Start from the configuration in table 1 and change it such that in the configurations with $q^{h}, c^{h}, q^{h}, c^{l}$ the providers play $C$ instead of $E$. This is an equilibrium.

Indeed in table 1 with the adaptions in the corollary, we have that $q^{C}=q^{h}$ and $q^{E}=q^{l}$. Hence, we find that $q^{C}-q^{E}>c^{h}-c^{l}$ and $\mathrm{C}$ can be sustained. However, this equilibrium is not efficient as some patients visit the high cost provider in the configuration $q^{h}, c^{h}, q^{h}, c^{l}$.

Summarizing, we have seen the following. In the BW set-up with a monopoly insurer, there always exists an equilibrium in exclusive contracts. This equilibrium is not efficient as it is biased towards the cheap provider. If high quality is costly, the inefficiency of selective contacting is substantial. If quality differences are big enough compared to cost differences, there also exists an efficient equilibrium. In this equilibrium, the insurer signals high quality by contracting both providers. But an efficient equilibrium does not always exist.

\section{Insurer competition}

This section shows that insurer competition can increase efficiency. The main result is that an efficient equilibrium always exists with two insurers. That is, also for parameter values where there is no efficient equilibrium with a monopoly insurer.

The intuition why competition helps to improve efficiency is the following. Recall that with a monopoly insurer an efficient common equilibrium is destroyed if the exclusion rents are too high. Insurer competition helps to reduce rents from exclusion because the deviating insurer (who accepts an exclusive contract) has to compete with an insurer offering provider choice. If consumers value access to both providers, such a deviation to selective contracting is not profitable for an insurer. A monopoly insurer switching to an 
exclusive contract has no other insurer to compete with. This mechanism forms the basis of the following result.

Proposition 2 With insurer competition, there exists an efficient equilibrium.

Because there is a competing insurer offering a broad network, deviating to selective contracting is no longer profitable. Hence, there is always an equilibrium in common contracts in the configurations labeled $\mathrm{C}$ in table 1 .

The proof of this proposition uses very intense - Bertrand style - competition to establish that there is always an efficient equilibrium. We want to argue that intense competition is not only a sufficient condition for efficiency but also necessary.

In order to do this, we need to compare different equilibria. Hence, we need to be specific about what type of beliefs we allow to derive an equilibrium. We restrict attention to beliefs satisfying the following three requirements. First, consumer beliefs are only determined by the offered contract constellation. That is, consumer beliefs consist of $\left(q^{E}, q^{C}, \tilde{q}^{E}, \tilde{q}^{C}\right)$ only where $q^{E}\left(q^{C}\right)$ is the believed quality if only exclusive (common) contracts are offered and $\tilde{q}^{E}\left(\tilde{q}^{C}\right)$ is the believed quality of the exclusive (common) contract if one exclusive and one common contract are offered by insurers. To illustrate, this rules out beliefs that depend on premiums. Second, insurers have passive beliefs when observing off equilibrium path offers from providers (Hart et al., 1990; Segal, 1999). Third, we concentrate on equilibria where on the equilibrium path both insurers offer the same type of contract (either common or exclusive) which seems natural given the symmetry of our setup

We call this class PACD (Passive And Configuration Dependent beliefs) equilibria 11 The lemma shows that within this class of equilibria, efficiency implies Bertrand type competition in configurations where exclusive contracts are used.

Lemma 1 If - in a given configuration $\left(q_{1}, c_{1}, q_{2}, c_{2}\right)$ with $c_{1} \leq c_{2}$ - both providers offer only exclusive contracts in an efficient PACD equilibrium, a Bertrand outcome results: $p_{i}^{E} \leq c_{2}, t_{i}^{E}=0(i=1,2)$ and industry profits $\Pi^{E} \leq c_{2}-c_{1}$.

Hence efficiency in our model depends on intense competition. The next section considers different forms of market power and shows that market power tends to reduce efficiency.

\footnotetext{
${ }^{11}$ The proof of proposition 2 constructs a PACD equilibrium that is efficient. Hence, efficient PACD equilibria exist in our model.
} 
We conclude this section with a discussion of transitions between common and selective contracting regimes. Selective contracting was introduced in the US in the 1980s. Initially, the cost reductions that followed selective contracting were seen as showing the success of this policy. However, then the "managed care backlash" happened: patients started to prefer more inclusive hospital networks. In response to this, provider networks tended to broaden again (Dranove, 2011; Lesser et al., 2003). How can we interpret this shifting between regimes in our framework?

One way to think about a shift from one regime to the next, is to fix the regimes per configuration. For concreteness, assume that we are in the efficient equilibrium of table 1. Hence, if in a geographical region the cost-quality configuration of providers changes, the optimal contracting outcome (selective vs. common) can change as well. Although this can be a valid argument for some regions, it seems unlikely that this happened for all regions in the US in 1980s and 1990s that switched from common to selective contracting.

A second way to think about regime shift is equilibrium selection and consumers' expectations. To illustrate this, start with the equilibrium configuration in table 1. Now change the contracting outcome from $\mathrm{E}$ to $\mathrm{C}$ in the two patient critical configurations where both providers are high quality. This implies that $q^{C}=q^{h}$ and $q^{E}=q^{l}$ (see corollary 1). This can be sustained as equilibrium under both insurer monopoly and competition. Once people begin to realize that this is inefficient (in the patient critical configuration), providers can switch to $\mathrm{E}$ (which is always an equilibrium). Such a transition to efficiency is "helped along" if consumers understand that selective contracting does not need to imply low quality. That is, $q^{E}>q^{l}$.

But exactly because exclusive contracts are always an equilibrium, they can be implemented also in configurations where they are less efficient than common contracts. This is our interpretation of the managed care backlash. Networks were too restricted; broader networks would lead to higher welfare. Hence, insurers introduced more provider choice thereby signalling higher quality. As explained in the propositions, a switch from $\mathrm{E}$ to $\mathrm{C}$ is only possible if consumer beliefs satisfy $q^{C}>q^{E}$. In the case of the managed care backlash, such beliefs are well documented, e.g. Brodie et al. (1998); Blendon et al. (1998).

We come back to this in the policy section where we discuss recent attempts by the Dutch ministry of health to "stimulate" selective contracting. 


\section{Market power}

In this section, we show that market power distorts quality signalling and hence tends to reduce welfare in health care markets.

\section{1. insurer market power}

A simple way to capture the effects of insurer market power is to compare insurer duopoly with monopoly. Propositions 1 and 2 then show that insurer market power reduces efficiency in the following sense: with insurer monopoly there are parameter values where an efficient equilibrium does not exist, while with insurer competition there is always an efficient equilibrium. Hence, moving from insurer monopoly to insurer competition can raise welfare.

\section{2. provider market power}

There are two ways here to think of provider market power. The first is to consider the case where there is only one provider. Trivially, efficiency is reduced in this case as there is only one draw of quality and cost, while with competition there are two draws and in an efficient equilibrium the best of these draws prevails.

The second way to capture provider market power is to return to lemma 1 with insurer competition: to get efficiency, the equilibrium must be very competitive. In fact, there are other PACD equilibria which yield higher provider profits but are not efficient. Here we capture market power by allowing providers to coordinate ("collude") on an equilibrium with higher profits. For some parameter values, the (incentive compatible) collusion involves a correlated equilibrium.

Proposition 3 For any efficient PACD equilibrium, there is another PACD equilibrium yielding higher industry profits but lower welfare.

The relevant comparison here is between the common premium $p^{C}$ and the cost difference $\left|c_{1}-c_{2}\right|$ because $\left|c_{1}-c_{2}\right|$ is the (upper-bound on) industry profit using exclusive contracts; see lemma 1. If $p^{C}$ is high compared to the cost difference, softening competition by playing $\mathrm{C}$ instead of $\mathrm{E}$ is attractive for providers. That is, providers prefer an equilibrium with $C$ in the patient critical configuration - where efficiency demands E, but

$\Pi^{E}$ is low. If, instead, $p^{C}$ is small compared to the cost difference, providers prefer an 
equilibrium with $\mathrm{E}$ in the insurer critical configuration - where $\mathrm{C}$ maximizes welfare. As the high quality provider has high costs, industry profits are then maximized by selectively contracting the low cost provider. Consequently, for any parameter configuration there is an inefficient equilibrium leading to higher profits than the efficient equilibrium.

\section{Extension: Dynamic efficiency}

Up until now we have considered static efficiency. Although a complete analysis of dynamic efficiency is beyond the scope of this paper, we can generalize and even strengthen two important results of the paper in a simple dynamic framework 12 (i) insurance monopoly leads to inefficiency and (ii) with insurer competition we can get an efficient outcome. To show this result, we use the model with $m=n=2$.

Assume that each provider $P_{i}(i=1,2)$ can invest $\gamma\left(\phi^{c}\right) \geq 0$ to get $c^{l}$ with probability $\phi^{c}$ and $c^{h}$ with $1-\phi^{c}$. Similarly, investing $\gamma\left(\phi^{q}\right)$ gives $q^{h}$ with probability $\phi^{q}$ and $q^{l}$ with probability $1-\phi^{q} 13$ We assume that there exists $\underline{\phi} \in[0,1\rangle$ such that $\gamma(\underline{\phi}), \gamma^{\prime}(\underline{\phi})=0$ and $\gamma^{\prime \prime}(\phi)>0$ for $\phi>\underline{\phi}$. Further, $\gamma^{\prime}(1)=+\infty$. Given the investments, the draws of $c$ and $q$ are independent.

In this setting, efficiency consists of two components. First, static efficiency (as before): a welfare maximizing provider has to be used with probability 1 for each realization of qualities and costs. Second, dynamic efficiency: both providers have to undertake the welfare maximizing investments.

We want to compare symmetric private and social incentives to invest in cost and quality improvements. Table 2 gives the value added of a configuration $q, c$ for $P_{1}$ conditional on the configuration $q, c$ of $P_{2}$ in the column. To illustrate, if $P_{2}$ has $q^{l}, c^{l}$, the value added of $P_{1}$ having $q^{h}, c^{h}$ (instead of $\left.q^{l}, c^{h}\right)$ equals $q^{h}-c^{h}-\left(q^{l}-c^{l}\right)=\Delta q-\Delta c$ where $\Delta q$ denotes $q^{h}-q^{l}$. If $P_{1}$ has $q^{l}, c^{h}$ its social value added equals 0 for each realization of $q^{2}, c^{2}$ etc.

The welfare maximizing investment $\phi^{q}$ for $P_{1}$ equates the marginal investment costs and the expected marginal social value added of improving quality from $q^{l}$ to $q^{h}$ (conditional on $P_{2}$ using the optimal $\phi^{c}$ and $\phi^{q}$ and $P_{1}$ using the optimal $\left.\phi^{c}\right)$. $P_{1}$ 's profit maximization, however, will equate the marginal investment costs with the expected marginal profit gain

\footnotetext{
${ }^{12}$ The multiplicity of equilibria is one reason why a full analysis would take us too far from the main signalling story of the paper.

${ }^{13}$ Everything in this section goes through if the cost functions for $\phi^{q}$ and $\phi^{c}$ are not the same.
} 
from improving quality from $q^{l}$ to $q^{h}$. This indicates that the profit maximizing investment is not necessarily the efficient one. The following result focuses on the monopoly insurer setting and shows that requiring dynamic efficiency indeed limits the possibilities for an efficient outcome even further (compared to proposition 1). Put differently, the statically efficient equilibrium (even if it exists) does not induce dynamically efficient investments.

Table 2: Social value added of $P_{1}$ 's configuration $q, c$ conditional on $q^{2}, c^{2}$

\begin{tabular}{|c|c|c|c|c|}
\hline \multirow{2}{*}{$\begin{array}{l}\text { social value } \\
\text { added by } P_{1}\end{array}$} & \multirow[b]{2}{*}{$q^{l}, c^{l}$} & \multicolumn{3}{|c|}{$P_{2}$} \\
\hline & & $q^{h}, c^{l}$ & $q^{l}, c^{h}$ & $q^{h}, c^{h}$ \\
\hline$q^{l}, c^{l}$ & 0 & 0 & $\Delta c$ & 0 \\
\hline$P_{1} \quad q^{h}, c^{l}$ & $\Delta q$ & 0 & $\Delta q+\Delta c$ & $\Delta c$ \\
\hline$q^{l}, c^{h}$ & 0 & 0 & 0 & 0 \\
\hline$q^{h}, c^{h}$ & $\Delta q-\Delta c$ & 0 & $\Delta q$ & 0 \\
\hline
\end{tabular}

We characterize investment incentives for the case where providers 1 and 2 offer socalled partial substitutes (Rey and Tirole, 2007, pp. 2199) as in BW. That is, $\Pi^{1}+\Pi^{2} \geq \Pi^{C}$ where $\Pi^{i}$ denotes industry profits if the insurer has an exclusive contract with provider $i=1,2$ and $\Pi^{C}$ if the insurer contracts both providers.

Proposition 4 Take a monopoly insurer and assume $\Pi^{1}+\Pi^{2} \geq \Pi^{C}$. Consider the efficient equilibrium depicted in table 11 where providers use undominated strategies 14 Then there is under-investment in quality. There can be over- and under-investment in cost reductions.

There are two effects causing the under-investment in quality. First, there is an appropriability effect. The social incentive to increase $q$ is related to $\Delta q$. However, in terms of profits, the difference between (perceived) high (common) and low (exclusive) quality is $q^{C}-q^{E}<\Delta q$. Consider a high quality provider competing with a low quality provider. In the common outcome, perceived quality equals $q^{C}=q^{h}$. If the low quality provider deviates and only offers an exclusive contract to the insurer, perceived quality equals $q^{E}>q^{l}$. Hence, the high quality provider can only appropriate $q^{C}-q^{E}<\Delta q$.

\footnotetext{
${ }^{14}$ Following proposition 1, the statically efficient equilibrium exists only if $\Delta q \geq \Delta c\left(1+\frac{2\left(\phi^{q}\right)^{2} \phi^{c}\left(1-\phi^{c}\right)}{\left(1-\phi^{q}\right)^{2}}\right)$. We assume that $\gamma$ and $\underline{\phi}$ are such that this condition holds, i.e. the inefficiency in this proposition stems only from the dynamic efficiency requirement.
} 
Second, there is a signalling profit: a provider who does not treat anyone makes a strictly positive profit due to her signalling value. To see this, consider the common outcome in the insurer-critical configuration. The social value of $P_{1}$ with $q^{l}, c^{l}$ when $P_{2}$ has $q^{h}, c^{h}$ equals 0 as $P_{1}$ does not treat anyone (patients visit high quality $P_{2}$ ). But $P_{1}$ is contracted by the insurer to signal high quality. Intuitively, by joining the network with $P_{2}, P_{1}$ raises the consumer's perception of quality (and thereby raises industry profits) from $q^{E}$ to $q^{C} . P_{1}$ is able to capture this increase in profits. This reduces $P_{1}$ 's incentive to increase quality.

This signalling profit can cause either under- or over-investment in cost reductions. First, consider the case where $P_{2}$ has $q^{h}, c^{h}$. The social value of $P_{1}$ with $q^{h}$ reducing costs from $c^{h}$ to $c^{l}$ equals $\Delta c$. However, $P_{1}$ with $q^{h}, c^{h}$ already earns the signalling profit $q^{C}-q^{E}$ while her social value equals 0 (given that $P_{2}$ is $q^{h}, c^{h}$ ). This tends to lead to under-investment in cost reduction. Second, if $P_{2}$ has $q^{h}, c^{l}$ then the social value of $P_{1}$ with $q^{h}$ reducing costs from $c^{h}$ to $c^{l}$ is 0 . But when both $P_{1}$ and $P_{2}$ have $q^{h}, c^{l}, P_{1}$ earns the signalling profit. This tends to lead to over-investment in cost reduction. Which effect dominates depends on the details of the function $\gamma$.

As explained in section 3, there is an equilibrium where selective contracting is used in all configurations. The insurer then always contracts the lowest cost provider; irrespective of quality. Providers anticipating this selective contracting outcome have no incentive to raise quality, but investing to become the lowest cost provider is profitable. This is our interpretation of the claim by Porter and Teisberg (2006) (cited in the Introduction) that managed care led to a focus on cost cutting at the expense of quality.

We showed in the static setup that an efficient PACD equilibrium always exists with insurer competition. This result extends to the dynamic setting. That is, with insurer competition there is an equilibrium that is both statically efficient and features the right incentives for quality enhancement and cost reductions.

Proposition 5 In an insurance duopoly, there exists a PACD equilibrium that is efficient both from a static and dynamic point of view.

The intuition is that the two distortions with a monopoly insurer (appropriability effect and signalling profit) can be eliminated with insurer competition. First, consider again high quality $P_{1}$ with low quality $P_{2}$ in a common outcome with $q^{C}=q^{h}$. If an insurer accepts the exclusive contract from $P_{2}$, consumers see one insurer with a common 
contract and one with an exclusive contract. If consumer beliefs satisfy $q^{C}=q^{h}, \tilde{q}^{E}=q^{l}$, the deviating insurer can only capture $q^{l}$ and $P_{1}$ appropriates $q^{C}-\tilde{q}^{E}=\Delta q$, which is the social value added of $P_{1}$ 's quality.

Second, with insurer competition there exists an equilibrium where signalling profits are eliminated for a provider that does not treat anyone. That is, in the insurer critical configurations, the low quality provider in the common outcome receives zero profits. If this provider would try to demand a strictly positive profit from an insurer, the insurer would reject this deviating offer for fear of being priced out of the (insurance) market by his competitor.

\section{Conclusion and policy implications}

This paper provides a theoretical framework to think about selective contracting in health insurance markets and the effects on health care quality and costs. We conclude with a discussion of recent attempts to stimulate selective contracting in the Netherlands.

Traditionally, all health insurers in the Netherlands offer common contracts. Insurers tended to cover more than $90 \%$ of providers in the country. The Dutch ministry of health believes that insurers should be more selective in their contracting and focus on high quality providers with low costs. Part of the ministry's campaign is "cheap talk": explaining to a sceptical public that reducing provider choice is a "good thing" by raising health care quality and reducing costs. On a substantive level, the proposal is to change article 13 of the health insurance act 15 According to this article, an insurer does not need to reimburse a customer fully when she visits a provider outside of the network; but the reimbursement should not be so low as to prevent this from happening altogether. Up to now, insurers tend to cover $85 \%$ of the cost if a customer visits a provider out of their network. The change in this article allows insurers to provide zero reimbursement for visits outside of their network. The ministry believes that this change will stimulate insurers to contract more selectively than they used to.

Two questions can be asked about this: (i) can selective contracting be "stimulated" and, if so, (ii) is this desirable? As explained in our discussion of managed care in the US (section 4), we think of shifts between common and exclusive contracting as changing equilibrium. So, indeed, it is important to manage expectations. If consumers believe that

\footnotetext{
${ }^{15}$ See http://www.rijksoverheid.nl/documenten-en-publicaties/kamerstukken/2012/03/26/kamerbrief-over-aanpass
} 
$q^{C}-q^{E}$ is big under insurer monopoly or $\tilde{q}^{C}-\tilde{q}^{E}$ under insurer competition, it is not profitable for insurers to contract selectively. Indeed, if one insurer switches to E while the other sticks with $\mathrm{C}$, the former loses customers. This expectations effect can be mitigated by explaining that selective contracting is not necessarily bad, although it reduces provider choice for the insured. The ministry is correct that this message is important in changing expectations.

Under the current regime, insurers face this expectation problem and in addition still need to reimburse if their customers go outside the network. Consequently, there is not much incentive for insurers to contract selectively, even if it were desirable. Hence, changing article 13 of the health insurance law will indeed make it easier for insurers to contract selectively.

This brings us to the second question: is stimulating selective contracting welfare enhancing? As explained in corollary 1, there can be excessive common contracting in equilibrium. In particular, if common contracts are used in the patient critical configuration in which both providers have high quality. This is inefficient as patients use a high cost provider although a low cost provider with the same quality exists. The Dutch policy can then be interpreted as an attempt to change consumers' beliefs in order to facilitate the transition to an efficient equilibrium. This is likely to be the case if all Dutch hospitals have similar quality and mainly differ in costs.

However, in the latter case, it is inconsistent to argue - as the ministry does - that selective contracting will raise quality. The model shows that exclusive contracts cannot be used to exclude inefficient, low quality providers in equilibrium. In fact, exclusive contracts do not signal high but low quality in equilibrium. This is contrary to the naive intuition that insurers would use exclusive contracts to single out the high quality provider and punish low quality providers by not contracting with them. Further, selective contracting is efficient in case quality and costs are negatively correlated at the provider level (well run hospitals have both high quality and low costs). However, if quality and costs are positively correlated (quality requires resources), selective contracting tends to reduce welfare as insurers tend to contract low price (low quality) providers.

Finally, there is the question whether an efficient equilibrium can be sustained for all configurations in the Dutch health care market. We showed that efficient contracting is an equilibrium if insurer competition is intense enough. In the Dutch health insurance market, four insurers share almost $90 \%$ of the market. Moreover, concentration is even higher at 
the regional level 16 It is, therefore, unclear whether competitive forces in the health insurance market are strong enough to lead to an efficient equilibrium. Put differently, the underlying problem might not be the contracting regime but the competitiveness of the health insurance market.

\footnotetext{
${ }^{16}$ The Hirschman-Herfindahl index for the province Friesland, for example, was 6028 in 2014; see http://www.nza.nl/104107/105773/953131/Marktscan_Zorgverzekeringsmarkt_2014_en_Beleidsbrief.pdf page $17-19$.
} 


\section{A. Proofs}

Proof of proposition 1. (a) We show that an efficient equilibrium exists if (6) is satisfied. Table 1 shows which type of contract is used in an efficient equilibrium in each configuration.

Note that, regardless of the underlying configuration, an exclusive contract must have the same premium: as the consumer cannot observe the underlying configuration, the monopolist would otherwise deviate by charging the highest premium used in any E configuration also in the other E configurations. The same holds true for the common contract. Hence, there is only one exclusive premium $\sigma^{E}$ and one common premium $\sigma^{C}$. Using Bayes' rule and the equilibrium summarized in table 1, the consumer expects quality $q^{C}=q^{h}$ when offered a common contract and quality $q^{E}$ given by (5) when offered an exclusive contract. Consequently, the insurer chooses the profit maximizing premium $\sigma^{E}=q^{E}$ and $\sigma^{C}=q^{C}$. To describe the equilibrium completely, the equilibrium offers of the providers have to be specified. As noted above, these offers are not unique. However, here we show existence of an equilibrium and choose the offers that support this equilibrium. This is the equilibrium where providers use undominated strategies.

- E configurations: both providers bid a price of $\max \left\{c^{1}, c^{2}\right\}$ for an exclusive contract and do not offer common contracts. The insurer accepts the offer of the provider with the lower costs (and picks an arbitrary provider if $c^{1}=c^{2}$ )

- $\mathrm{C}$ configurations: define industry profits when only provider 1 is contracted as $\Pi^{1}=$ $q^{E}-c^{1}$, when only 2 is contracted as $\Pi^{2}=q^{E}-c^{2}$ and when both are contracted (common outcome) as

$$
\Pi^{C}=q^{C}- \begin{cases}c^{1} & \text { if } q^{1}>q^{2} \\ c^{2} & \text { if } q^{2}>q^{1} \\ \frac{1}{2}\left(c^{1}+c^{2}\right) & \text { if } q^{1}=q^{2} .\end{cases}
$$

For the $\mathrm{C}$ configurations, we distinguish two cases:

1. If $\Pi^{1}+\Pi^{2} \geq \Pi^{C}$ (this is the case with partial substitutes (Rev and Tirole, 2007, pp. 2199) analyzed in BW), provider $i$ offers a common contract with a fixed fee of $t^{i}=\Pi^{C}-\Pi^{j}$ where $j \neq i$ and a variable price of $p^{i}=c^{i} 17$ Furthermore, provider

\footnotetext{
${ }^{17} \mathrm{~A}$ fixed fee is paid if the consumer buys the common contract. The variable price is paid to provider $i$ if the consumer buys the common contract and seeks treatment at provider $i$.
} 
$i$ offers an exclusive contract at price $p^{i}=c^{i}, t^{i}=\Pi^{C}-\Pi^{j}$. Hence, the profits of provider $i$ are $\Pi^{C}-\Pi^{j}$ and insurer profits are $\Pi^{1}+\Pi^{2}-\Pi^{C} \geq 0$. As the insurer is indifferent between accepting the $\mathrm{C}$ contracts and either $E$ contract, providers cannot profitably deviate by demanding higher $p^{i}$ or $t^{i}$.

2. If $\Pi^{1}+\Pi^{2}<\Pi^{C}$ the problem is simpler. Each provider $i$ demands her outside option $\Pi^{i}$ plus a share of the surplus $\Pi^{C}-\Pi^{1}-\Pi^{2}>0$. We assume that the providers split the surplus 50:50. That is, provider $i$ offers a common contract with a fixed fee $t^{i}=\Pi^{i}+\left(\Pi^{C}-\Pi^{1}-\Pi^{2}\right) / 2$ and a variable price of $p^{i}=c^{i}$. Furthermore, provider $i$ offers an exclusive contract with the same $p^{i}, t^{i}$. Hence, insurer profits are 0 and provider $i$ 's profits are $\Pi^{i}+\left(\Pi^{C}-\Pi^{1}-\Pi^{2}\right) / 2$.

In both cases, the insurer accepts the common contract.

We have to check that this is an equilibrium. The consumer is indifferent between buying and not buying the insurance policy. Hence, buying it is optimal. In the E configurations, the insurer is indifferent between the two exclusive contracts. Hence, accepting the one from the low cost provider is optimal. In the first case of the $\mathrm{C}$ configuration, the insurer is indifferent between the $\mathrm{C}$ and $\mathrm{E}$ contracts and accepting the common contract is optimal. In the second case of the C-configurations, the insurer makes zero profits when accepting the common contracts. If he accepted the exclusive contract of provider $i$ instead, his profits would be $\Pi^{i}-t^{i}-c^{i}=\left(\Pi^{1}+\Pi^{2}-\Pi^{C}\right) / 2-c^{i}<0$. Hence, the insurer behaves optimally.

To see that the provider offers are optimal, note that any provider whose contract offer is accepted cannot ask for a higher price or fixed fee as the insurer would then reject the offer. In the $\mathrm{C}$ configurations, a provider cannot do better by not offering a common contract: if he did, he would have to match the other provider's exclusive contract offer in order to be contracted. In case 1, note that the equilibrium profits of provider $i$ plus the equilibrium profits of the insurer equal $\Pi^{i}$. Since $\Pi^{i}$ is the industry profit achieved by an exclusive contract with provider $i$, no deviation to an exclusive contract can make both the insurer and provider $i$ better off. As the insurer can obtain the same payoff as in equilibrium by accepting provider $j$ 's exclusive contract, there is no profitable deviation for provider $i$. In case 2 , the provider $i$ has a higher payoff in equilibrium than $\Pi^{i}$ and consequently deviations to an exclusive contract cannot be profitable.

The last possible deviation we have to check is non-participation, i.e. we have to 
check that expected equilibrium profits are non-negative in every configuration. This is obvious in the $\mathrm{E}$ configurations and also in the $\mathrm{C}$ configurations if case 2 applies. In case 1, equilibrium profits are non-negative if $\Pi^{C}-\Pi^{i}=q^{C}-q^{E}+c^{i}-c^{C} \geq 0$ (where $c^{C}$ are the expected provider costs in the common contract). Note that $q^{C}-q^{E}+c^{i}-c^{C}$ is smallest in the insurer-critical configuration with $i$ being the low cost provider. That is, if $\Pi^{C}-\Pi^{i} \geq 0$ in the insurer-critical constellation, then the same holds for all $\mathrm{C}$ configurations in table 1 and all players. $\Pi^{C}-\Pi^{i} \geq 0$ for low cost provider $i$ in the critical constellation is equivalent to

$$
\begin{aligned}
q^{h}-\frac{2 f\left(q^{h}, c^{h}, q^{h}, c^{l}\right) q^{h}+q^{l} \sum_{x, y \in\left\{c^{h}, c^{l}\right\}} f\left(q^{l}, x, q^{l}, y\right)}{2 f\left(q^{h}, c^{h}, q^{h}, c^{l}\right)+\sum_{x, y \in\left\{c^{h}, c^{l}\right\}} f\left(q^{l}, x, q^{l}, y\right)}+c^{l}-c^{h} \\
=\left(q^{h}-q^{l}\right) \frac{\sum_{x, y \in\left\{c^{h}, c^{l}\right\}} f\left(q^{l}, x, q^{l}, y\right)}{2 f\left(q^{h}, c^{h}, q^{h}, c^{l}\right)+\sum_{x, y \in\left\{c^{h}, c^{l}\right\}} f\left(q^{l}, x, q^{l}, y\right)}+c^{l}-c^{h} \geq 0
\end{aligned}
$$

where the last inequality is equivalent to (6). This concludes the proof that an efficient equilibrium exists if (6) is satisfied.

(b) We now show that no efficient equilibrium exists if (6) does not hold. As discussed earlier, efficiency requires that a common contract is offered in the insurer critical configuration. The low cost firm in the insurer critical configuration must then have an incentive not to deviate to an exclusive contract (while not offering a common contract). A necessary condition for the non-profitability of such a deviation is that the total industry profit in the common contract $\left(\Pi^{C}\right)$ is greater than the industry profits that the low cost provider and the insurer could obtain with an exclusive contract $\left(\Pi^{i}\right) 18$ Put differently, in the insurer critical constellation $\Pi^{C}-\Pi^{i}=q^{C}-c^{h}-q^{E}+c^{l} \geq 0$ has to hold where $i$ is the low cost provider. This inequality is most likely to hold if the equilibrium is such that $q^{C}-q^{E}$ is as high as possible. The bold entries in table 1 are required by efficiency. Note that all other entries are chosen such that $q^{C}-q^{E}$ is maximal (i.e. a common contract is used in a configuration if this leads to high quality care and an exclusive contract is used otherwise). Hence, the inequality $q^{C}-c^{h}-q^{E}+c^{l} \geq 0$ is most likely satisfied in an efficient equilibrium if the equilibrium is of the type depicted in table 1. As shown in (a), the inequality $q^{C}-c^{h}-q^{E}+c^{l} \geq 0$ is in this type of equilibrium equivalent to (6). Hence, this necessary condition for an efficient equilibrium is violated whenever (6) does not hold.

Q.E.D.

\footnotetext{
${ }^{18}$ Common equilibrium exists if and only if $\Pi^{C} \geq \Pi^{i}$ for each $i=1,2$ (BW page 70/1). This is a condition on industry profits and does not depend on whether or not providers use weakly dominated strategies.
} 
Proof of proposition 2, We propose the following equilibrium play 19 In insurercritical constellations, the welfare maximal provider $i$ offers a common contract at variable price $c^{i}$ to both insurers. Furthermore, $i$ offers an exclusive contract at variable price $c^{i}$. The minimal cost provider $j$ offers a common contract at price 0 and an exclusive contract at price $c^{i}$. Both insurers accept the common contracts and offer a common contract to consumers at premium $\sigma=c^{i}$.

In all non-insurer-critical configurations both providers offer to each insurer an exclusive contract at variable price $\max \left\{c^{1}, c^{2}\right\}$. Insurers accept the exclusive contract of the provider with the lowest cost (and the offer of provider 1 if costs are equal) and charge a premium equal to $\sigma=\max \left\{c^{1}, c^{2}\right\}$ to consumers.

We follow Hart et al. (1990); Segal (1999) in assuming that insurers have passive beliefs off the equilibrium path: if an insurer receives an offer from a provider that is not the equilibrium offer, he will still believe that the other insurer got the equilibrium offer from this provider 20 If an insurer receives two exclusive offers, he accepts the one with the lower price. If an insurer receives in an insurer critical configuration a non-equilibrium offer from provider $i$, he accepts the exclusive offer of $i$ if the deviation includes an exclusive contract at price $\tilde{p}<q_{1}-\left(q_{n}-\max \left\{c^{1}, c^{2}\right\}\right)$ (setting a premium of $\tilde{\sigma}=q_{1}-\left(q_{n}-\max \left\{c^{1}, c^{2}\right\}\right)$ for the exclusive contract in the consumer market) and he refuses all offered contracts otherwise. Consumers use Bayes' rule to derive $q^{E}$ (expected quality of an exclusive contract given the equilibrium strategies) and $q^{C}$ (expected quality of a common contract given equilibrium strategies) and buy one of the offered contracts. Consumers have the following off equilibrium path beliefs: if one insurer offers a common contract and the other insurer offers an exclusive contract, consumers expect the exclusive contract to have quality $\tilde{q}^{E}=q_{1}$ and the common contract to have quality $\tilde{q}^{C}=q_{n}$ (and then buy the contract that maximizes consumers' payoff). If both providers offer exclusive contracts with different providers, consumers attach quality $q^{E}$ to both providers. Clearly, consumers behave optimally given the equilibrium strategies of the other players (recall the assumption $c_{m}<$ $\left.q_{1}\right)$.

Insurers play a best response: given the premium setting of the other insurer, the only premium at which an insurer can sell at non-negative profits is the equilibrium premium. Hence, the premium setting is optimal. In insurer-critical configurations, insurer $k$ cannot

\footnotetext{
${ }^{19}$ This equilibrium does not use fixed fees but only variable prices. It is straightforward to see that deviations using fixed fees are not profitable in the here constructed equilibrium.

${ }^{20}$ This belief is not vital: there also exists an efficient equilibrium with, for example, symmetric beliefs.
} 
gain by deviating to an exclusive contract: in order to sell to consumers the premium has to be $q_{1}-\left(q_{n}-\max \left\{c^{1}, c^{2}\right\}\right)<\max \left\{c^{1}, c^{2}\right\}$. Hence, the premium of an exclusive contract would have to be lower than the price $p=\max \left\{c^{1}, c^{2}\right\}$ at which it is offered to the insurer in order to sell to the consumer. This implies that the deviation is not profitable. Given passive beliefs, the insurers' off equilibrium path strategies are also optimal. In particular, when a provider asks for a higher price in the common contract the insurer believes that the other insurer received the equilibrium offer and will charge the equilibrium premium. Hence, the insurer cannot sell at non-negative profits if he accepts a common contract at higher than equilibrium prices. Similarly, accepting an exclusive contract can only lead to non-negative profits if the price is less than $q_{1}-\left(q_{n}-\max \left\{c^{1}, c^{2}\right\}\right)$ (which is the premium the insurer has to set to sell an exclusive contract to the consumer given that the other insurer sells the equilibrium common contract). Consequently, it is optimal to reject all contracts in case of deviations not including an exclusive contract at price $\tilde{p}<q_{1}-\left(q_{n}-\max \left\{c^{1}, c^{2}\right\}\right)$.

Providers play a best response: in non-insurer-critical configurations, provider $i$ cannot charge a higher price as the insurer will then contract with provider $j$. Charging a lower price reduces the profits for the low cost provider and would lead to negative profits for the high cost provider. Consequently, deviating is not profitable in non-insurer-critical configurations. In insurer critical configurations, the only relevant deviation is one that leads to acceptance of an exclusive contract by (at least) one insurer. In order to have an insurer accept such a deviation, the price has to be $\tilde{p}<q_{1}-\left(q_{n}-\max \left\{c^{1}, c^{2}\right\}\right)$. But then the deviating provider's profits are $\tilde{p}-c^{i}<q_{1}-q_{n}+\max \left\{c^{1}, c^{2}\right\}-c^{i} \leq q^{i}-q^{j}+\max \left\{c^{1}, c^{2}\right\}-c^{i}<$ 0 where the last inequality follows from the definition of an insurer critical configuration. Hence, such a deviation is not profitable. All other deviations are rejected and therefore cannot be profitable.

Proof of lemma 1. Take an arbitrary candidate equilibrium. The consumer's belief is by assumption $q^{E}$ given that only exclusive contracts are offered. Let $k \in\{A, B\}$ denote one insurer that has weakly lower expected profits than the other insurer in the candidate equilibrium (in the given configuration). Note that insurers compete in homogenous good Bertrand competition in the premium setting stage (and in equilibrium each insurer must have correct expectations concerning the premium of the other). Hence, profits of $k, \pi_{k}$, in the candidate equilibrium must be zero. Similarly, let $i \in\{1,2\}$ denote one provider that has weakly lower expected profits than the other provider in the candidate equilibrium. 
Consequently, $\pi_{i}+\pi_{k}=\pi_{i} \leq \Pi / 2$ where $\pi_{i}$ are the profits of $i$ and $\Pi$ is the industry profit in the candidate equilibrium. Denote the premium in the candidate equilibrium by $\sigma^{*}$ and the expected costs of the provider used by the consumer (in the given configuration) as $c^{*}$. Consider the deviation offer by $i$ to $k$ consisting of $\tilde{p}_{i}^{E}=\sigma^{*}-\varepsilon-\pi_{k}=\sigma^{*}-\varepsilon, \tilde{t}_{i}^{E}=0$. Given $k$ 's passive beliefs it is optimal for $k$ to accept this deviation offer as by setting a premium of $\sigma^{\prime} \in\left(\sigma^{*}-\varepsilon, \sigma^{*}\right)$ he gets deviation profits of $\sigma^{\prime}-\sigma^{*}>0=\pi^{k}$. The deviation is clearly profitable for $i$ if $c^{i} \leq c^{*}$ and $\sigma^{*}>\max \left\{c^{1}, c^{2}\right\}$ as his deviation profits are then higher than $\Pi / 2$ (for $\varepsilon>0$ small enough). If $c^{i}>c^{*}$, then the deviation is profitable for $i$ (for $\varepsilon>0$ small enough) if $\sigma^{*}-c^{i}>\pi_{i}$ which is clearly true if $\sigma^{*}>\max \left\{c^{1}, c^{2}\right\}$ and $\pi_{i}=0$. This leaves the last case $\pi_{i}>0$ and $c^{i}>c^{*}$ : we will now argue that this last case cannot occur in an efficient PACD equilibrium: note that $i$ would have to sell to consumers if $\pi_{i}>0$ (if $i$ got only fixed payments, the insurer paying these fixed payments would be better off rejecting $i$ 's contract). But this would be inefficient as $c^{*}<c^{i}$ implies that $i$ is not the lowest cost provider. Consequently, the non-profitability of the deviation implies that $\sigma^{*} \leq \max \left\{c^{1}, c^{2}\right\}$ both when $c^{i} \leq c^{*}$ (first case) and when $c^{i}>c^{*}$ (second and third case).

Q.E.D.

Proof of proposition 3. This proof uses the following result.

Lemma 2 Take a PACD equilibrium $\Gamma$ in which consumers have beliefs $\left(q^{C}, q^{E}, \tilde{q}^{C}, \tilde{q}^{E}\right)$. If $q^{C}$ increases ceteris paribus, then there is a PACD equilibrium $\Gamma^{\prime}$ with at least as high industry profits as $\Gamma$.

Proof. For this proof, fix a particular configuration in which a common contract is used according to $\Gamma$ (if there is no such configuration the statement is obviously true). The proposed $\Gamma^{\prime}$ will differ from $\Gamma$ only in this configuration. The statement is trivially true if the constraint $p^{C} \leq q^{C}$ is not binding in $\Gamma$ as $\Gamma$ remains an equilibrium if $q^{C}$ increases then. Hence, assume that $p^{C}=q^{C}$ and that one insurer, say A, has an incentive to increase $p^{C}$ if $q^{C}$ was higher (assuming that all other equilibrium contracts stay fixed). Note that this implies that B does not exert competitive pressure in the initial equilibrium; i.e. B offers a common contract at a premium above $q^{C}$ (by the definition of PACD equilibria B offers a common contract). This implies that $\pi^{B}=0$ in $\Gamma$.

First, consider the case where $\pi^{A}=0$ in $\Gamma$. Then there is an equilibrium $\Gamma^{\prime}$ which differs from $\Gamma$ only in so far that both providers offer the same contract to $B$ as they do to $A$. Hence, $B$ exerts competitive pressure and $A$ will not find it optimal to raise $p^{C}$ if 
$q^{C}$ increases as he would then lose all demand to $B$. Note that $B$ will obtain 0 profits by accepting the offered contracts: either the consumer contracts with $B$ and then $B$ 's profits are zero because $\pi^{A}=0$ in $\Gamma$; or the consumer contracts with $A$ and then $B$ 's profits are zero as all prices are per contracted consumer. There are also no profitable deviations in $\Gamma^{\prime}$ for the providers (or for $A$ ) because there were no profitable deviations in $\Gamma$.

Second, consider the case where $\pi^{A}>0$ in $\Gamma$. Since $\Gamma$ is a PACD equilibrium this implies that $A$ is indifferent between accepting the common contract and an exclusive contract offered by provider $i$ : otherwise, provider $j \neq i$ would have a profitable deviation in which he increases the fixed fee (in both his common and exclusive offer) by $\varepsilon>0$. As $A$ has passive beliefs, it would still be optimal for him to accept the common contract offer after this deviation. Next, note that $\pi^{i} \geq \tilde{q}^{E}-c^{i}-\max \left\{\tilde{q}^{C}-q^{C}, 0\right\}$ has to hold as provider $i$ can otherwise profitably deviate with an exclusive contract offer to $B$ (recall that $\pi^{B}=0$ in $\Gamma$ ).

Now let equilibrium $\Gamma^{\prime}$ be such that provider $i \in\{1,2\}$ offers the common contract $t^{C^{\prime}}=\pi^{i}+\pi^{A} / 2, p^{C^{\prime}}=c^{i}$ and the exclusive contract $t^{E^{\prime}}=\pi^{i}+\pi^{A} / 2, p^{E^{\prime}}=c^{i}$ to both insurers. Both insurers accept the common contracts and set a premium equal to $q^{C}$ as $q^{C}=p^{C}=\pi^{1}+\pi^{2}+\pi^{A}+c^{C}$ (where $c^{C}$ is the expected cost in the common contract in the given configuration). Both insurers reject off equilibrium path offers unless those offers give a strictly positive expected profit given their passive beliefs. $\Gamma^{\prime}$ is an equilibrium: since $A$ was indifferent between the common and the exclusive contracts in $\Gamma$, he would still be indifferent if $B$ got the same offers as in $\Gamma$. As $B$ offers in equilibrium a more attractive contract to the consumer in $\Gamma^{\prime}$ than in $\Gamma$, a deviation to accepting the exclusive contract is less attractive for $A$ while the relative attractiveness of the common contract is unchanged: recall that in the common contract $A$ is already constrained by $p^{C} \leq q^{C}$ and the fact that $B$ offers the common contract also at price $q^{C}$ does not pose an additional constraint to $A$. Hence, $A$ prefers the common contract to the exclusive contract in $\Gamma^{\prime}$. As $B$ gets the same offer as $A, B$ also prefers the common to the exclusive contract. Provider $i$ would only gain by a deviation to an exclusive contract if $\pi^{i}+\pi^{A} / 2<\tilde{q}^{E}-c^{i}-\max \left\{\tilde{q}^{C}-q^{C}, 0\right\}$. This, however, is impossible as $\pi^{i} \geq \tilde{q}^{E}-c^{i}-\max \left\{\tilde{q}^{C}-q^{C}, 0\right\}$ (see above) and $\pi^{A}>0$. Clearly, changing the price of the common contract cannot increase a provider's profits. Hence, $\Gamma^{\prime}$ is an equilibrium in which equilibrium profits are the same as in $\Gamma$ and $\pi^{A}=\pi^{B}=0$. As $B$ exerts competitive pressure on $A$ the constraint $q^{C} \geq p^{C}$ is not binding in the sense that an insurer would not like to increase the premium if $q^{C}$ increases. Hence, $\Gamma^{\prime}$ is also 
an equilibrium if $q^{C}$ increases ceteris paribus.

Q.E.D.

We prove the proposition for the case $m=n=2$ first and explain in the end how it extends to $m, n \geq 2$. Implicitly, the following proof assumes that if $q^{C}$ increases ceteris paribus, then there is a PACD equilibrium in which industry profits are at least as high as before the increase. This follows from lemma 2 above.

Every efficient equilibrium has to give a common contract in insurer-critical configurations. Furthermore, efficiency requires that exclusive contracts are used in patient critical configurations. We show that for any efficient equilibrium $\Gamma^{*}$ either an equilibrium $\Gamma^{\prime}$ where a common contract is used in patient critical configuration $\left(q^{h}, c^{l}, q^{h}, c^{h}\right)$ or an equilibrium $\Gamma^{\prime \prime}$ where an exclusive contract is used (with some probability) in the insurer critical configuration leads to higher industry profits.

Consider $\Gamma^{\prime}$ that is identical to $\Gamma^{*}$ with the exception that in the configuration $\left(q^{h}, c^{l}, q^{h}, c^{h}\right)$ the same common contract as in the insurer critical configuration is used. The nonprofitability of deviations in the critical configuration ensures also that deviations are unprofitable in $\Gamma^{\prime}$. Depending on $\Gamma^{*}$, using a common contract in $\left(q^{h}, c^{l}, q^{h}, c^{h}\right)$ might increase $q^{C}$ and decrease $q^{E}$. Because of lemma 1 the decrease in $q^{E}$ does not lead to lower profits in the configurations where exclusive contracts are used. This lemma also implies that $\Gamma^{*}$ leads to industry profits less or equal to $c^{h}-c^{l}$ in the configuration $\left(q^{h}, c^{l}, q^{h}, c^{h}\right)$. Hence, $\Gamma^{\prime}$ leads to higher profits than $\Gamma^{*}$ if $p^{C}>\frac{3 c^{h}-c^{l}}{2}$ (note that costs are higher in $\Gamma^{\prime}$ compared to $\Gamma^{*}$ as with probability $1 / 2$ consumers use the high cost provider).

In case $p^{C} \leq \frac{3 c^{h}-c^{l}}{2}$, we claim that $\Gamma^{\prime \prime}$ leads to higher profits than $\Gamma^{*}$. Let $\Gamma^{\prime \prime}$ be identical to $\Gamma^{*}$ with one exception:

In the insurer critical configuration $\left(q^{h}, c^{h}, q^{l}, c^{l}\right), \Gamma^{\prime \prime}$ uses exclusive contracts that lead to industry profits $c^{h}-c^{l}$ with probability $\alpha>0$ (while still using the common contract from $\Gamma^{*}$ with probability $1-\alpha$ ).

By $p^{C} \leq \frac{3 c^{h}-c^{l}}{2}, p^{C}<q^{C}$ in $\Gamma^{*}$ : to see this note that the deviation to an exclusive contract must not be profitable. An exclusive offer $\tilde{p} \leq p^{C}-\left(q^{C}-\tilde{q}^{E}\right), \tilde{t} \in\left[0, p^{C}-\right.$ $\left.\left(q^{C}-\tilde{q}^{E}\right)-\tilde{p}\right\rangle$ will be accepted given the passive beliefs. We take the toughest case $\tilde{q}^{E}=q^{l}$. A necessary condition for the non-profitability of such a deviation is $\Pi^{C}-\tilde{\Pi}=$ $\left(p^{C}-c^{h}\right)-\left(p^{C}-\left(q^{C}-q^{l}\right)-c^{l}\right) \geq 0$. Given that the deviation cannot be profitable in equilibrium, we get $q^{C} \geq q^{l}+c^{h}-c^{l} \geq 2 c^{h}-c^{l}>\frac{3 c^{h}-c^{l}}{2}$. Therefore $p^{C}<q^{C}$ and the consumer still buys the common contract in $\Gamma^{\prime \prime}$ if $\alpha>0$ is not too big even if $q^{C}$ is lower 
in $\Gamma^{\prime \prime}$ (which may or may not be the case depending on $\Gamma^{*}$ ) 21

Furthermore, $p^{C} \leq \frac{3 c^{h}-c^{l}}{2}$ implies that industry Bertrand profits $c^{h}-c^{l}$ are higher than the profits earned in the configuration $\left(q^{h}, c^{h}, q^{l}, c^{l}\right)$ in $\Gamma^{*}$ which are $p^{C}-c^{h} \leq \frac{c^{h}-c^{l}}{2}<$ $c^{h}-c^{l}$.

Extension to $m, n \geq 2$ : by assumption, there is always an insurer critical constellation in the general $m, n \geq 2$ case. Take an arbitrary critical configuration and label the two qualities and costs defining this critical constellation $q^{h}, q^{l}, c^{h}, c^{l}$. Then change an arbitrary efficient PACD equilibrium $\Gamma^{*}$ in the same way as done in the $m=n=2$ case. This gives a PACD equilibrium with higher industry profits.

Proof of proposition 4. Before proving the proposition, note that $q^{l}-c^{h} \geq \Delta q$ is a sufficient condition for $\Pi^{1}+\Pi^{2} \geq \Pi^{C}$. To see this, combine $q^{l}-c^{h} \geq \Delta q$ with $q^{E}>q^{l}$ and $q^{C}=q^{h}$; then $\Pi^{1}+\Pi^{2} \geq \Pi^{C}$ for any configuration 22

$\Pi^{1}+\Pi^{2} \geq \Pi^{C}$ implies that the equilibrium profits of provider $i$ are his marginal contribution $\Pi^{C}-\Pi^{j}$ with $j \neq i$; see BW. Table A1 gives $P_{1}$ 's profits for this efficient equilibrium.

Comparing this table with table 2, the under-/over-investment in cost reduction can be seen as follows. When looking at the difference in payoffs between $c^{h}$ and $c^{l}$ (for given quality of $P_{1}$ ), the $\Delta c$ terms are the same in the two tables with two exceptions: (i) when $P_{2}$ has $q^{h}, c^{l}$ and $P_{1}$ has $q^{h}$; then $P_{1}$ 's profits increase with $q^{C}-q^{E}$ when reducing costs (while social value added does not change) and (ii) when $P_{2}$ has $q^{h}, c^{h}$ and $P_{1}$ has $q^{h}$; then $P_{1}$ 's profits increase with $\Delta c-\left(q^{C}-q^{E}\right)$ when reducing costs (while value added increases with $\Delta c$ ). Therefore, over-investment in cost reductions results if and only if $\phi^{c}-\left(1-\phi^{c}\right)>0$ which depends on the specific $\gamma$ and $\underline{\phi}$.

Next, consider the incentive to raise quality. There are three reasons why we have under-investment in this case. First, the private incentive to raise quality is driven by $q^{C}-q^{E}$ while the social incentive is driven by $\Delta q>q^{C}-q^{E}$. Second, when $P_{2}$ has $q^{h}, c^{l}$ and $P_{1}$ has $c_{h}, P_{1}$ makes positive profits with $q^{l}$ while profits are zero with $q^{h}$; this gives

\footnotetext{
${ }^{21}$ One might wonder whether there are sufficient conditions for $\alpha=1$ which implies that providers do not have to correlate their offers. We provide three such conditions: First, $q^{l}-c^{h} \geq\left(c^{h}-c^{l}\right) / 2$ is sufficient as this condition together with $p^{C} \leq \frac{3 c^{h}-c^{l}}{2}$ implies $p^{C} \leq q^{C}$ in $\Gamma^{\prime \prime}$ with $\alpha=1$. Second, $q^{C}=q^{h}$ in $\Gamma^{*}$ as $q^{C}$ is then still $q^{h}$ in $\Gamma^{\prime \prime}$ with $\alpha=1$ and therefore $p^{C}<q^{C}$. Third, $f\left(q^{h}, c^{h}, q^{l}, c^{l}\right)$ sufficiently low as then changing from $\Gamma^{*}$ to $\Gamma^{\prime \prime}$ will affect $q^{C}$ only very little.

${ }^{22}$ Recall that $\Pi^{i}=q^{E}-c^{i}$ is the industry profit achievable through an exclusive contract with provider $i$.
} 
Table A1: $P_{1}$ 's profits in configuration $q, c$ conditional on $q^{2}, c^{2}$ in efficient equilibrium with monopoly insurer

\begin{tabular}{ll|llll}
\multicolumn{2}{c|}{$P_{1}$ 's profits } & \multicolumn{5}{|c}{$P_{2}$} \\
& & $q^{l}, c^{l}$ & $q^{h}, c^{l}$ & $q^{l}, c^{h}$ & $q^{h}, c^{h}$ \\
\hline \multirow{3}{*}{$P_{1} \quad q^{l}, c^{l}$} & 0 & $q^{C}-q^{E}$ & $\Delta c$ & $q^{C}-q^{E}$ \\
& $q^{h}, c^{l}$ & $q^{C}-q^{E}$ & $q^{C}-q^{E}$ & $q^{C}-q^{E}+\Delta c$ & $\Delta c$ \\
& $q^{l}, c^{h}$ & 0 & $q^{C}-q^{E}$ & 0 & $q^{C}-q^{E}$ \\
& $q^{h}, c^{h}$ & $q^{C}-q^{E}-\Delta c$ & 0 & $q^{C}-q^{E}$ & $q^{C}-q^{E}$
\end{tabular}

a negative incentive to raise quality while the social incentive is zero in this case. Third, when $P_{2}$ has $q^{h}, c^{h}$ and $P_{1}$ has $c^{l}$. Then the social incentive to raise quality equals $\Delta c$, while the private incentive equals $\Delta c-\left(q^{C}-q^{E}\right)$ which is less. Hence, for each configuration (where incentives differ) the social incentive exceeds the private incentive. Therefore, the market under-invests in quality.

Q.E.D.

Proof of proposition 5. We construct an efficient PACD equilibrium that uses in each configuration the contract type depicted in table 1. We want to construct the equilibrium such that the payoffs of the two providers in each configuration are given by table A2. These payoffs are such that the difference from one configuration to the other reflects the difference in welfare (assuming that the efficient provider is used in every configuration). If we can sustain these payoffs in equilibrium it is therefore obvious that the efficient $\phi^{c}$ and $\phi^{q}$ are chosen.

Table A2: $\quad P_{1}$ and $P_{2}$ 's profits in configuration $q, c$ in efficient equilibrium with insurer competition

\begin{tabular}{ll|llll}
\multicolumn{2}{c|}{ provider } & \multicolumn{5}{|c}{$P_{2}$} \\
& & $q^{l}, c^{l}$ & $q^{h}, c^{l}$ & $q^{l}, c^{h}$ & $q^{h}, c^{h}$ \\
\hline \multirow{3}{*}{$P_{1}$} & $q^{l}, c^{l}$ & 0,0 & $0, \Delta q$ & $\Delta c, 0$ & $0, \Delta q-\Delta c$ \\
& $q^{h}, c^{l}$ & $\Delta q, 0$ & 0,0 & $\Delta q+\Delta c, 0$ & $\Delta c, 0$ \\
& $q^{l}, c^{h}$ & $0, \Delta c$ & $0, \Delta q+\Delta c$ & 0,0 & $0, \Delta q$ \\
& $q^{h}, c^{h}$ & $\Delta q-\Delta c, 0$ & $0, \Delta c$ & $\Delta q, 0$ & 0,0
\end{tabular}

Equilibrium play is as follows: in each configuration, providers make offers that will give them the profits in table $\mathrm{A} 2$ (under the assumption that the configuration-contracting 
rule is as in table 1).

In the configuration $\left(q^{h}, c^{h}, q^{l}, c^{l}\right)$, both providers offer a common contract and $P_{1}$ demands payment of $\Delta q-\Delta c+c^{h}$ in the common contract while $P_{2}$ demands 0 payments in the common contract. Additionally, both providers offer an exclusive contract at their own cost level. The insurers accept the common contracts and charge both a premium of $\Delta q-\Delta c+c^{h}$.

In the configuration $\left(q^{l}, c^{l}, q^{l}, c^{h}\right)$, both providers offer an exclusive contract at variable price $c^{h}$ to both insurers. Both insurers accept the exclusive contract of $P_{1}$ and set a premium of $c^{h}$.

In other configurations, equilibrium play is similar: the two insurers receive the same offers and compete in Bertrand fashion. The specific offers are determined by tables 1 and A2. Whenever common contracts are used in equilibrium, providers also offer exclusive contracts at their own cost level.

Consumers' off path beliefs are $\tilde{q}^{C}=q^{C}=q^{h}$ and $\tilde{q}^{E}=q^{l}$. Insurers have passive beliefs off the equilibrium path and reject all off equilibrium path offers that do not yield them a strictly positive profit (given their passive beliefs).

Now we have to check whether anyone can profitably deviate. First, check whether given the offers - it is optimal for the insurers to accept the equilibrium contracts. This is obvious in configurations where exclusive contracts are used. Let's look at the insurer critical configuration $\left(q^{h}, c^{h}, q^{l}, c^{l}\right)$ : accepting $P_{2}$ 's exclusive offer is - given the passive beliefs - only profitable if $0<\left(\tilde{q}^{E}-\tilde{q}^{C}+\Delta q-\Delta c+c^{h}\right)-c^{l}=0$ which is not the case. Next we check the configuration $\left(q^{h}, c^{l}, q^{l}, c^{l}\right)$. Deviating to one of the exclusive contracts is only profitable if $0<\left(\tilde{q}^{E}-\tilde{q}^{C}+\Delta q+c^{l}\right)-c^{l}=0$ which does not hold. The same calculation can be done in the other configurations and consequently it is optimal for the insurers to accept the equilibrium offers.

Second, consider deviations in which providers simply ask for a higher price. By the passive belief assumption, it is optimal for an insurer to reject such a deviation contract: as the provider is believed to still provide the equilibrium contract to the other insurer, an insurer would not sell if accepting the deviating offer. In combination with the previous paragraph, a provider can also not sell exclusive contracts after such deviations (in configurations where common contracts are offered in equilibrium). Hence, rejecting all contracts from a provider deviating in this way is optimal and therefore the provider does not have an incentive to set higher prices. 
Third, consider a deviation where a provider offers only an exclusive contract in a configuration where common offers are offered in equilibrium. For the same reasons as in the previous paragraph, it is optimal for an insurer with passive beliefs to reject these offers (unless the exclusive contract is priced below costs which is obviously not a profitable deviation).

Q.E.D. 


\section{References}

Bardey, D. and J.-C. Rochet (2010). Competition among health plans: A two-sided market approach. Journal of Economics \& Management Strategy 19(2), 435-451.

Bernheim, B. D. and M. Whinston (1998). Exclusive dealing. Journal of Political Economy 106(1), 64-103.

Bijlsma, M. E., J. Boone, and G. Zwart (2009). Selective contracting and foreclosure in health care markets. CEPR Discussion Paper (7576).

Blendon, R. J., M. Brodie, J. M. Benson, D. E. Altman, L. Levitt, T. Hoff, and L. Hugick (1998). Understanding the managed care backlash. Health Affairs 17(4), 80-94.

Brodie, M., L. A. Brady, and D. E. Altman (1998). Media coverage of managed care: is there a negative bias? Health Affairs 17(1), 9-25.

Chernew, M. E. and J. P. Newhouse (2011). Chapter one - health care spending growth. In T. G. M. Mark V. Pauly and P. P. Barros (Eds.), Handbook of Health Economics, Volume 2 of Handbook of Health Economics, pp. 1 - 43. Elsevier.

Cutler, D. (2004). Your money or your life: strong medicine for America's healthcare system. Oxford University Press.

Cutler, D. M., M. McClellan, and J. P. Newhouse (2000). How does managed care do it? The RAND Journal of Economics 31(3), pp. 526-548.

Dranove, D. (2000). The economic evolution of American health care: from Marcus Welby to managed care. Princeton University Press.

Dranove, D. (2011). Chapter ten - health care markets, regulators, and certifiers. In T. G. M. Mark V. Pauly and P. P. Barros (Eds.), Handbook of Health Economics, Volume 2 of Handbook of Health Economics, pp. 639 - 690. Elsevier.

Dranove, D., S. M., and W. White (1993, April). Price and concentration in hospital markets: the switch from patients-driven to payer-driven competition. Journal of Law and Economics 36(1), 179-204.

Gaynor, M. (2006, June). What do we know about competition and quality in health care markets? Working Paper 12301, National Bureau of Economic Research. 
Hart, O., J. Tirole, D. Carlton, and O. Williamson (1990). Vertical integration and market foreclosure. Brookings Papers on Economic Activity. Microeconomics 1990, 205-286.

Himmelstein, D., S. Woolhandler, I. Hellander, and S. Wolfe (1999). Quality of care in investor-owned vs not-for-profit hmos. JAMA 282(2), 159-163.

Lesser, C. S., P. B. Ginsburg, and K. J. Devers (2003, February). The end of an era: What became of the "managed care revolution" in 2001? Health Services Research 38(1), 337355.

Liebman, J. and R. Zeckhauser (2008, September). Simple humans, complex insurance, subtle subsidies. Working Paper 14330, National Bureau of Economic Research.

Ma, C.-T. A. and T. G. McGuire (2002, Spring). Network incentives in managed health care. Journal of Economics \& Management Strategy 11(1), 1-35.

McGuire, T. G. (2011a). Chapter 25 - physician agency and payment for primary medical care. In S. Glied and P. Smith (Eds.), Oxford Handbook of Health Economics, Oxford Handbook of Health Economics, pp. 602-623. Oxford University Press.

McGuire, T. G. (2011b). Chapter five - demand for health insurance. In T. G. M. Mark V. Pauly and P. P. Barros (Eds.), Handbook of Health Economics, Volume 2 of Handbook of Health Economics, pp. 317-396. Elsevier.

Muir, M. A., S. A. Alessi, and J. S. King (2013, February). Clarifying costs: Can increased price transparency reduce healthcare spending? Technical Report 38, UC Hastings Research Paper.

Pear, R. (2014, July 19). To prevent surprise bills, new health law rules could widen insurer networks. New York Times.

Porter, M. E. and E. O. Teisberg (2006). Redefining health care: creating value-based competition on results. Boston, Massachusetts: Harvard Business School Press.

Rey, P. and J. Tirole (2007). Chapter 33 a primer on foreclosure. Volume 3 of Handbook of Industrial Organization, pp. 2145 - 2220. Elsevier.

Rey, P. and T. Vergé (2004, Winter). Bilateral control with vertical contracts. RAND Journal of Economics 35(4), 728-746. 
Segal, I. (1999). Contracting with externalities. Quarterly Journal of Economics 114, $337-388$.

Stone, D. A. (1997). The doctor as businessman: The changing politics of a cultural icon. Journal of Health Politics, Policy and Law 22(2), 533-556.

Terhune, C. (2013, September 14). Insurers limiting doctors, hospitals in health insurance market. Los Angeles Times.

Zwanziger, J., G. A. Melnick, and A. Bamezai (2000, October). The effect of selective contracting on hospital costs and revenues. Health Services Research 35(4), 849-867. 